\title{
Potential Role of Acacia Senegal (Gum Arabic) as Immunomodulatory Agent among newly diagnosed COVID 19 Patients: A structured summary of a protocol for a randomised, controlled, clinical trial
}

Lamis Kaddam ${ }^{1,2^{*}}$ D, Rasha Babiker ${ }^{3}$, Sara Ali ${ }^{4}$, Shahinaz Satti ${ }^{1}$, Nour Ali $^{5}$, Maha Elamin $^{6}$, Mowaia Mukhtar ${ }^{7}$, Mustafa Elnimeiri $^{8}$ and Amal Saeed ${ }^{9}$

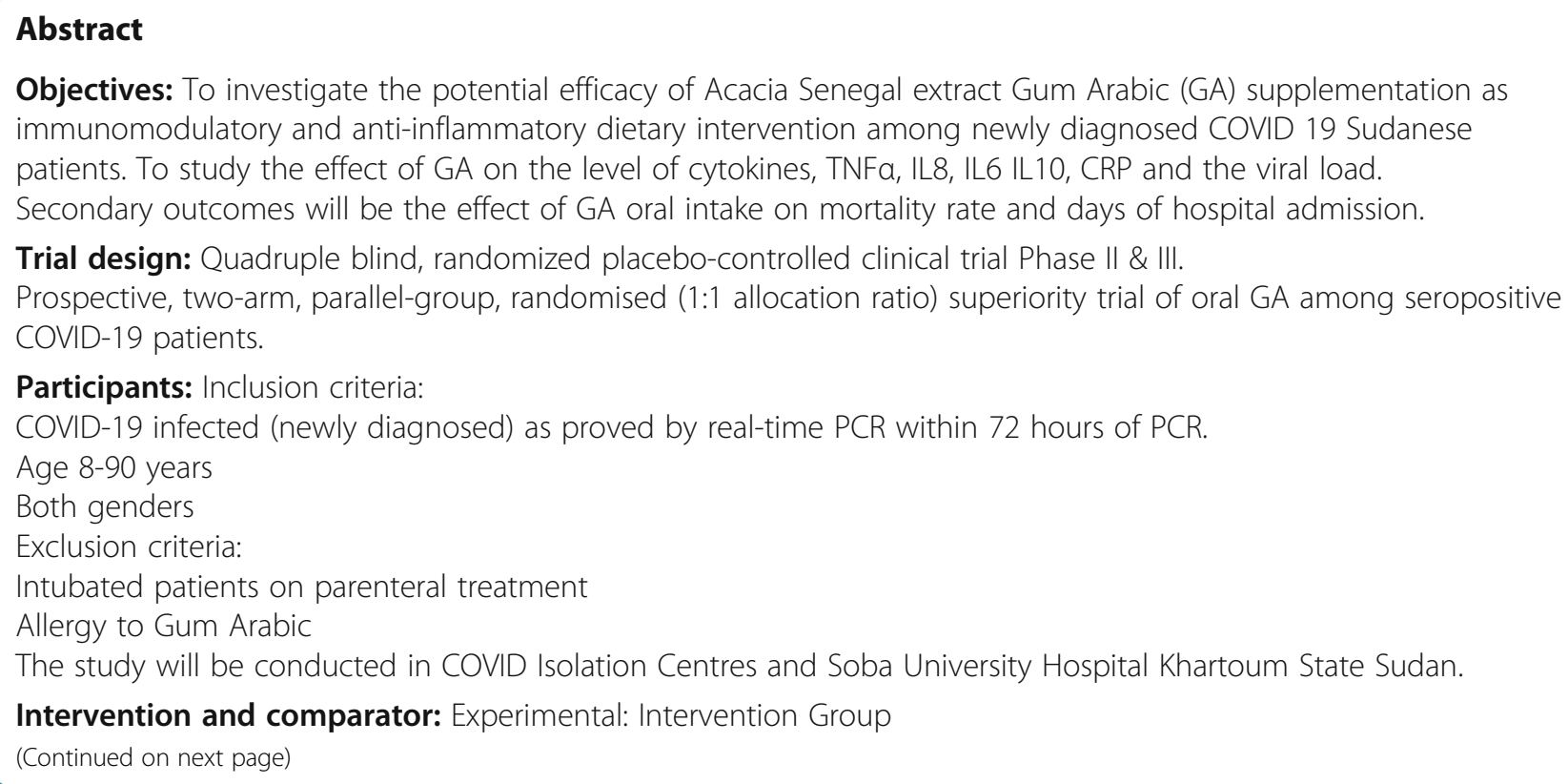

\footnotetext{
* Correspondence: lamiskaddam@hotmail.com

'Department of Physiology, Faculty of Medicine, Alneelain University Khartoum, P.O. Box: 11121, 12702 Khartoum, Sudan

${ }^{2}$ Present Address: Department of Physiology, Faculty of Medicine, King Abdul-Aziz University, Rabigh, Saudi Arabia

Full list of author information is available at the end of the article
}

(c) The Author(s). 2020 Open Access This article is licensed under a Creative Commons Attribution 4.0 International License, which permits use, sharing, adaptation, distribution and reproduction in any medium or format, as long as you give appropriate credit to the original author(s) and the source, provide a link to the Creative Commons licence, and indicate if changes were made. The images or other third party material in this article are included in the article's Creative Commons licence, unless indicated otherwise in a credit line to the material. If material is not included in the article's Creative Commons licence and your intended use is not permitted by statutory regulation or exceeds the permitted use, you will need to obtain permission directly from the copyright holder. To view a copy of this licence, visit http://creativecommons.org/licenses/by/4.0/ The Creative Commons Public Domain Dedication waiver (http://creativecommons.org/publicdomain/zero/1.0/) applies to the data made available in this article, unless otherwise stated in a credit line to the data. 
(Continued from previous page)

This arm will receive 100\% natural Gum Arabic provided in a powder form in 30-grams-dose once daily for four weeks Placebo Comparator: Control group: This group will be provided with pectin powder provided as one-gram-dose once daily for four weeks

Both GA and placebo will be in addition to standard care treatment based on local clinical guidelines.

Main outcomes: Mean change from baseline score of Immune Response to end of the trial. Changes of the level of Tumor Necrosis Factor (TNFa), interleukin IL8, IL6, and IL10 from the baseline values (Four weeks from the start of randomization).

Mortality rate: The percentage of deaths among COVID 19 patients received Gum Arabic compared to placebo (Four weeks from the start of randomization]).

Randomisation: Randomization (1:1 allocation ratio) and will be conducted using a sequence of computer-generated random numbers by an independent individual.

Each participating centre will be assigned a special code generated by the computer. The randomization will be kept by the $\mathrm{PI}$ and a research assistant.

Blinding (masking): Quadruple (Participant, Care Provider, Investigator, Outcomes Assessor)

Numbers to be randomised (sample size): 110 eligible patients will be randomly assigned to either GA ( $\mathrm{n}=55$ ) or placebo $(n=55)$ groups.

Trial Status: Protocol Version no 2,30 ${ }^{\text {th }}$ June 2020. Recruitment will start on $15^{\text {th }}$ September 2020. The intended completion date is $15^{\text {th }}$ January 2021.

Trial registration: ClinicalTrials.gov Identifier: NCT04381871. Date of trial registration: 11 May 2020.

Full protocol: The full protocol is attached as an additional file, accessible from the Trials website (Additional file 1). In the interest in expediting dissemination of this material, the familiar formatting has been eliminated; this Letter serves as a summary of the key elements of the full protocol.

Keywords: COVID-19, Randomised controlled trial, protocol, Gum Arabic, cytokines, Immunomodulation

\section{Supplementary information}

Supplementary information accompanies this paper at https://doi.org/10. 1186/s13063-020-04707-2.

Additional file 1. Full Study Protocol.

\section{Acknowledgements}

We would like to thank Dar Savanna Ltd. Khartoum, Sudan (www. naturegums.com) for providing gum Arabic as a gift for the study, with no future role or intervention in the design of the study and collection, analysis, and interpretation of data and in writing the manuscript. We would like to acknowledge Dr. Nashwa Eassa Dean of Scientific Deanship Alneelain University for the logistic support throughout the study.

\section{Authors' contributions}

$L K, R B, S S$ and $M N$ participated in the study design. $L K, R B, M N, M E, S S$ and AS will be involved in all aspects of the study conduction. RB, SS, NA, and SA will collect the data from the centres. MM and SA will conduct the laboratory work. LK, RB, NE, ME and MN will analyse the data. All authors approved the final version of the manuscript.

\section{Funding}

This research is funded by a grant from Higher Education and Scientific Research Ministry in Sudan to LK and ME

\section{Availability of data and materials}

The datasets used and/or analysed during the current study will be available from the corresponding author on reasonable request

\section{Ethics approval and consent to participate}

The study was approved by the Central Institutional Review Board at Al -Neelain University 23 ${ }^{\text {rd }}$ April 2020 (NUM-IRP-20-09-04-1). We confirm that this trial has received ethical approval from the appropriate ethical committee described above. Written informed consent will be obtained from each participant prior to enrolment or from the legal guardian for patients aged less than 18 years old

\section{Consent for publication}

Not applicable.

\section{Competing interests}

The authors declare that they have no competing interests.

\section{Author details}

${ }^{1}$ Department of Physiology, Faculty of Medicine, Alneelain University Khartoum, P.O. Box: 11121, 12702 Khartoum, Sudan. ${ }^{2}$ Present Address: Department of Physiology, Faculty of Medicine, King Abdul-Aziz University, Rabigh, Saudi Arabia. ${ }^{3}$ Department of Physiology, Faculty of Medicine, National University-Sudan, Khartoum, Sudan. ${ }^{4}$ Department of Microbiology, Faculty of Medical Laboratory Sciences, International University of Africa, Khartoum, Sudan. ${ }^{5}$ Department of Physiology, Faculty of Medicine, Nile University, Khartoum, Sudan. ${ }^{6}$ Department of Biochemistry, Faculty of Medicine, Alneelain University, Khartoum, Sudan. ${ }^{7}$ Institute of Endemic Diseases, Faculty of Medicine, University of Khartoum, Khartoum, Sudan. ${ }^{8}$ Department of Community Medicine, Faculty of Medicine, Alneelain University, Khartoum, Sudan. ${ }^{9}$ Department of Physiology, Faculty of Medicine, University of Khartoum, Khartoum, Sudan.

Received: 24 August 2020 Accepted: 27 August 2020 Published online: 05 September 2020

\section{Publisher's Note}

Springer Nature remains neutral with regard to jurisdictional claims in published maps and institutional affiliations. 